\title{
Value of P300 as a screening tool of cognitive impairment in epilepsy: A prospective study from India
}

\author{
Amandeep Singh, Ajoy Kumar Sodani, Dinesh Chouksey, Rahul Jain \\ Department of Neurology, Sri Aurobindo Medical College and Post Graduate Institute, Indore, India
}

\begin{abstract}
Objective. Preservation of cognition is essential for good quality life. Epileptic pathological processes and pharmacotherapy are thought to be responsible for the cognitive dysfunction (CDF) in persons with epilepsy (PWE). Regular monitoring of persons on antiepileptic drugs (AED) for CDF is recommended. P300, an attention dependent event related potential (ERP), is known to be abnormal in PWE. The value of P300 in monitoring cognitive functions has not been tested prospectively.

Material and methods. PWE not exposed to AED in preceding 6 months were recruited and prescribed one of the three common AEDs i.e. carbamazepine, phenytoin and valproate. Subjective tests of cognition-MoCA, Trail making test, Paragraph memory tests, Stroop test in addition to P300 ERP were administered before initiating AED and repeated after three months on the prescribed AED. The significance of the change in the scores of cognitive tools and P300 latency was ascertained by paired t-test.

Outcome. Thirty eight PWE (females 18 , mean age mean $=22.89 \pm 9.39 \mathrm{yr}$ ) qualified the inclusion criterion. The values of P300 latency and deployed subjective tests of cognition at two data collection points were compared with the clinical profile of the patients. Performance of the patients deteriorated on all the cognitive batteries after exposure to AED (mean $107.84 \pm 19.2$ days). The deterioration was independent of education level, type of AED and seizures. Prolongation of P300 latency from baseline was seen in 30 of 38 patients $(78.94 \%)$. The sensitivity of P300 for picking cognitive dysfunction was $80.64 \%$ taking MoCA scores as a reference.

Conclusions. Attention along with several other domains of cognition is affected adversely with AED exposure. The P300 could be useful for monitoring cognitive adverse effects of AED in PWE.
\end{abstract}

Keywords: cognition, attention, ERP-P300, screening tool, epilepsy

\section{INTRODUCTION}

Attention is one of the important domains of cognitive function and is quintessential for activities like driving and learning. Persons with epilepsy (PWE) have higher prevalence of learning disability (LD) compared to general population which has been implicated to anti-epilepsy medication [1]. For this reason regular monitoring of cognitive functions has been recommended [2,3]. Neuropsychological batteries like Wechsler Adult intelligence scale, Mini-Mental score, Finger tapping, Stroop test (STR), Paragraph memory test (PrM) and Montreal Cognitive Assessment (MoCA) have been used for such monitoring.
MoCA is a validated tool which takes into consideration all six domains of cognition. It was developed and is used extensively to screen the persons suspected to have minimal cognitive dysfunction $[4,5]$. However this tool is said to have several limitations like need of specifically trained examiner and certain level of formal education for the examinee. Moreover, the MoCA scores are influenced by the social and cultural factors [6].

P300 wave, an event related potential (ERP) described by Sutton et al, is celebrated as an electrophysiological marker of cognitive function $[7,8]$. Latency of P300 wave does not depend upon the overall IQ, education level and, when recorded 
with odd-ball paradigm, is immune to the trans-cultural variation $[9,10]$.

P300 latency is known to correlate with the deteriorating cognitive faculties in conditions like dementia [9]. This ERP has been used to study subclinical cognitive dysfunction in PWE. Mar-Janku et al. evaluated 23 PWE with neuropsychological batteries and elicited P300 in them by odd-ball paradigm [11]. They found prolongation of P300 latency in all the subjects. This result did not correlate with that of the formal neuropsychological tests. Triantafyllou et al. and Kubota et al. examined P300 latency to identify cognitive dysfunction in epilepsy $[12,13]$. They found latency prolongation in subjects receiving anti-epileptic drugs (AED) and considered it to reflect cognitive dysfunction. However, in their experiment neuro-psychological tests were not used. In the previous studies the cognitive functions and the P300 latencies, in the patients with epilepsy, were evaluated at a single point of time during the course of the disease. Thus the duration of exposure to AED, prior to P300 elicitation, was not uniform [13-16]. Further, it is known in normal healthy persons, if exposed to AED, show P300 latency prolongation $[17,18]$. This prolongation has been attributed to AED (particularly polypharmacy), chronicity of epilepsy and to the seizure frequency $[13,14]$.

To best of our knowledge, the effect of AED on P300 and cognitive tests has not been prospectively evaluated before. We therefore set out to study the effect of AED on cognition in PWE and value of P300 ERP in identifying the cognitive decline. Additionally, we planned to study the effects of AED on attention according to disease duration, epilepsy type, drug prescribed, education level and demographic factors.

\section{MATERIAL AND METHODS}

The study was conducted at a teaching hospital attached to SAIMS Medical College and PG Institute in central India. After clearance from the institutional ethical committee, patients were prospectively recruited from the neurology outdoor, between January 2019 and April 2020. Forty five patients with non-progressive, non-syndromic epilepsy, were recruited initially, after applying following criterion: a) drug naïve or not received AED in previous six months, b) age between 15 and 55 years, c) no historical evidence of dementia and depression, d) no imaging evidence of neuronal migration disorder or malignant lesion or abnormal ventricular dilatation, and e) willing to provided written consent. Subjects had full right to withdraw from the study anytime during the study.

The subjects were started on the conventional AEDs phenytoin (PHT), carbamazepine (CBZ) and valproate (VPA) was prescribed as per discretion of the treating neurologist (DC). Those who did not take AED as prescribed and/or failed to show up for the follow-up assessment were excluded.

The subjective tests of cognition were administered to, and each candidate underwent the P300 ERP evaluation before initiation of the AED. The dose of which was slowly titrated upwards as per the need. Upon taking the maximum prescribed dose of AED for at least three months the patients were requested to return. Upon presentation for follow-up the end point was reached. The tests done at outset were repeated on reaching the end point as per the protocols given below.

\section{Cognitive testing}

Montreal Cognitive Assessment Test-MoCA test for overall cognitive evaluation: One of the investigators (AS) completed online MoCA training and permission to use the battery was obtained from the copyright owner [19]. Using the validated version of MoCA test in Hindi total MoCA score (MoCA-t) was initially calculated for each candidate [20]

Attention was evaluated using the Stroop test [21], time to complete trail making task [22], paragraph memory test [23]. The score of the attention domain of the MOCA was extracted, which has maximum possible score of six (MoCA-a). Those scoring $<2$ were excluded from further work up ( $\mathrm{n}=1$; figure 1).

\section{Stroop test}

It was performed after evaluating for color blindness by ishihara charts. For Stroop test, two cards were created locally, in Hindi, as per the previous investigators [21]. The Card 1 consists of color pictures of flowers with their color described underneath in different color (e.g. picture of yellow flower while yellow flower printed with blue ink). It presents sixteen such pictures and words in grid of $4 \times 4$. The subject was required to name the 


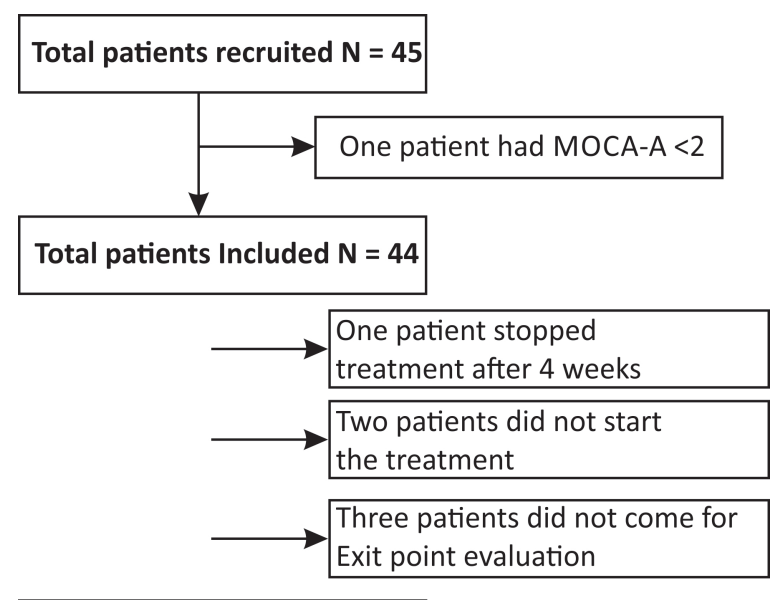

The study group $\mathbf{N}=38$

FIGURE 1. Exclusion and study population

color of the text written, ignoring the actual color of the flower and meaning of the text. The Card2 presents the names of color printed with ink of a different color (e.g. blue written in yellow ink, in a grid of $5 \times 5$ ). The subject was required to name the color of the ink. After pretest training with an example card, the test card was placed at a distance of four feet from the subject, who shall read out the card starting from left upper corner and going further horizontally, in one go. Number of errors was calculated. Each correct response was given one point for. Two set of scores were thus obtained i) Stroop-1 - score obtained on card1 out of maximum possible16; ii) Stroop-2, the scores from card2 (maximum 25).

\section{Trail making task (TMT)}

It is an integral to the MoCA test and was administered as the previously laid down method. [22] Additionally we recorded time taken to complete the trail making task using a commercially available stopwatch (Taksun digital sports stopwatch). For each patient the time required to complete the trail task was noted (in seconds).

\section{Paragraph memory test (PrM)}

For testing the immediate free recalls (FR), two stories in local vernacular language of 100 words each and with a mean of forty units of verbal information were selected. One of the stories was read to the subject at the rate of one word per second. The subject was asked to imagine itself in the described spatial setting and remember as many details as possible. FR was scored as the number of verbal information units recalled correctly, maximum being forty.

\section{P300 test}

It was performed on (Nicolet Viking version 12.0.0) as per the method used by Duncan et al. [24] At the outset patients hearing ability was screened using whispering test [25] and finger rub test [26]. Then the candidate was rested for 30 minutes in a quiet, semi dark, and acoustically shielded room. The procedure of the odd-ball paradigm was explained and training was imparted. Total three sets were recorded at $\mathrm{Fz}, \mathrm{Cz}, \mathrm{Pz}$ with A1-A2 reference. For each set 300 sweeps, consisting of rare stimuli $(70 \mathrm{db}, 1000 \mathrm{~Hz})$ and frequent stimuli $(55 \mathrm{db}, 500 \mathrm{~Hz})$, delivered 20:80 ratio, were used. The subject was asked to ignore the frequent stimuli and raise her left index finger every time a rare stimuli is heard. Eye movements were monitored separately by placing electrodes at the lateral canthus of right eye.

One of the investigator (AKS), blinded for the patients' demographic and AED details, studied the P300 data, discretely. He identified the best of the three sets for the analysis. The qualifying criterion for an acceptable set were : i) clear positive deflection, with identifiable peak, at or after 275 msec. post stimulus artifact, ii) maximum positivity at $\mathrm{Cz} / \mathrm{Pz}$, iii) reliably replicated with a clear preceding baseline [27]. The latency, from the stimulus artifact to the maximum positivity (peak), was noted.

\section{Data synthesis}

MoCA-t, MoCA-a, Stroop-1, Stroop-2, TMT, PrM scores and P300 latency value at entry and exit points were noted for each patient. The difference between the two points was taken into consideration for statistical analysis. The differential data of each of the above parameters was compared with age (15-30 and 31-55 years), gender (male/female), type of epilepsy (generalized/ localization related) AED prescribed (CBZ/PHT/ VPA), education ( $\leq 12$ standard or $>12$ ), duration of disease ( $\leq 6$ months $/>6$ months).

\section{Data analysis}

Proportions are given as percentages. SPSS software (Trial ver. 17.0) was used for the statistical analysis. Paired t test was applied to compare the entry and exit data. Comparison of means and proportions were calculated as and when required. 
Specificity and sensitivity of P300 latency for identifying cognitive dysfunction was calculated using MoCA-t score as a reference. A p value of $<0.05$ was considered significant.

\section{RESULTS}

Initially 45 patients were included of them 7 patients got excluded for the reasons given in fig.1, thus the final study group consisted of 38 subjects (study population, the average exposure to AED at exit point was $107.84 \pm 19.2$ days (median 101, range-90-179 days).

The mean age of the study population $(\mathrm{n}=38)$ was 22.89 \pm 9.39 years (median 20, range 15-55, female $\mathrm{n}=18,47.4 \%$ ). Most of the patients ( 37 of $38 ; 97.4 \%$ ) had two or more seizures in preceding 12 months and remained untreated/undiagnosed. One patient received the diagnosis of epilepsy five years back and thereafter took treatment only for the first year.

Majority of the patients (18 of 38, 47.37\%) were prescribed CBZ (Table 1). The number of the subjects in 15-30 yr group was significantly more (33 vs. $5 ; \mathrm{p}<0.0001)$. There was no statistically significant difference within the group as per the gender, education level, type and duration of epilepsy.

At entry none of the patient had clinical symptoms suggesting cognitive dysfunction. After introduction of AED, at the time of final follow-up at exit, 5 of 38 (13.15\%) complained of poor concentration and/or difficulty in calculations. At exit, the MOCA-t score deteriorated in $81.57 \%$ (31 of 38). Prolongation of P300 latency from baseline was seen in 30 of 38 patients (78.94\%). Of five clinically symptomatic in three patients the MOCA-t score did not change from that at entry. Although in these three subjects P300 latency prolongation was noted at follow-up. The mean value of different tests at entry and exit is provided in table 2 . The results suggest, that overall, the cognitive functions deteriorated, from base line, following exposure to AEDs.

The values of P300 latency and deployed subjective tests of cognition at two data collection points were compared with the clinical profile of the patients. The results are presented in tables 3 to 6. At exit point the MoCA-t and MoCA-a score significantly deteriorated for all the variables (ta-

TABLE 1. Demographic variables of study group $N=38$

\begin{tabular}{|c|c|c|c|}
\hline \multicolumn{2}{|c|}{ Variable } & \multirow{2}{*}{$\begin{array}{c}\mathbf{N}(\%) \\
33(86.8)\end{array}$} & \multirow{3}{*}{$\begin{array}{c}\begin{array}{c}\text { Significance* } \\
\text { (p-value) }\end{array} \\
<0.0001^{*}\end{array}$} \\
\hline \multirow{2}{*}{ Age $($ mean $=22.89 \pm 9.39)$} & $15-30 y r$ & & \\
\hline & $31-55 y r$ & $5(13.2)$ & \\
\hline \multirow{2}{*}{ Gender } & Male & $20(52.6)$ & \multirow{2}{*}{$0.65^{\mathrm{ns}}$} \\
\hline & Female & $18(47.4)$ & \\
\hline \multirow{2}{*}{ Epilepsy } & Primary generalized & $22(57.9)$ & \multirow{2}{*}{$0.17^{\mathrm{ns}}$} \\
\hline & Localization Related & $16(42.1)$ & \\
\hline \multirow{3}{*}{ AED } & Carbamazepine & $18(47.37 \%)$ & \multirow{3}{*}{-} \\
\hline & Phenytoin & $7(18.42 \%)$ & \\
\hline & Valproate & $13(34.21 \%)$ & \\
\hline \multirow{2}{*}{ Education } & $\leq 12^{\text {th }}$ standard & $23(60.5)$ & \multirow{2}{*}{$0.07^{\mathrm{ns}}$} \\
\hline & $>12^{\text {th }}$ standard & $15(39.5)$ & \\
\hline \multirow{2}{*}{ Duration of epilepsy } & $<6$ months & $17(44.73)$ & \multirow{2}{*}{$0.36^{\mathrm{ns}}$} \\
\hline & $>6$ months & $21(55.26)$ & \\
\hline
\end{tabular}

TABLE 2. Entry and exit value of attention parameters

\begin{tabular}{|l|c|c|c|}
\hline Variable $(\mathbf{n}=\mathbf{3 8})$ & Entry & Exit & Significance $\mathbf{p}$ value $[\mathrm{CI}]$ \\
\hline P300 $(\mathbf{m s e c})$ & $313.83 \pm 28.65$ & $339.59 \pm 45.15$ & $0.000^{*}[-38.53$ to- 12.98$]$ \\
\hline MoCA- t & $23.47 \pm 3.50$ & $21.45 \pm 3.67$ & $0.000^{*}[1.34$ to2.70] \\
\hline MoCA-a & $4.71 \pm 1.03$ & $3.53 \pm 1.28$ & $0.000^{*}[0.89$ to 1.47$]$ \\
\hline TMT (sec) & $52.81 \pm 40.83$ & $65.96 \pm 48.84$ & $0.005^{*}[-21.98$ to -4.32$]$ \\
\hline Stroop 1 & $14.37 \pm 1.65$ & $13.31 \pm 2.75$ & $0.015^{*}[0.21$ to. 88$]$ \\
\hline Stroop 2 & $22.55 \pm 2.21$ & $21.13 \pm 2.74$ & $0.001^{*}[0.60$ to2.23] \\
\hline Paragraph PrM & $20.45 \pm 6.55$ & $14.53 \pm 5.97$ & $0.000^{*}[3.99$ to7.85] \\
\hline
\end{tabular}


ble 4). Like MoCA-a and MoCA-t, patients' performance on PrM deteriorated on all the counts (table-5). Results suggest that different test fair differently when compared with MoCA -a and MoCA-t. For example the P300 latency prolongation in persons on PHT and those educated $>12$ standard was not statistically significant. The time taken to make a trail, the TMT test, was not affected significantly in females, in persons receiving CBZ, in those with disease duration of more than six months and in those with localization related epilepsy. In contrast, no significant affection of Stroop-1 was seen in generalized epilepsy group and those with $\leq 6$ month disease duration, while both Stoop-1 and Stroop-2 did not change significantly from baseline in 31-55 yr age group.

Sensitivity and specificity of P300 for identifying cognitive impairment was derived considering MoCA-t as the standard. Of the study population $(\mathrm{n}=38) 31$ subjects showed deterioration of MoCA-t score at exit. Of these 31, 25 patients showed prolongation of P300 latency on follow-up evalua-

TABLE 3. Effect of AED on P300 vs. patient profile

\begin{tabular}{|c|c|c|c|c|c|}
\hline \multicolumn{2}{|c|}{ Variables } & \multirow{2}{*}{$\begin{array}{c}\begin{array}{c}\text { P300 latency at } \\
\text { entry, msec } \pm s d\end{array} \\
312.6 \pm 28.69 \\
\end{array}$} & \multirow{2}{*}{$\begin{array}{c}\begin{array}{c}\text { P300 latency at exit, } \\
\text { msec } \pm \text { sd }\end{array} \\
340.51 \pm 47.47\end{array}$} & \multirow{2}{*}{$\begin{array}{c}\begin{array}{c}\text { Significance } \\
\text { (t-test, p-value) }\end{array} \\
0.0005^{*} \\
\end{array}$} & \multirow{2}{*}{$\begin{array}{c}95 \% \mathrm{Cl} \\
(-) 42.5-(-) 13.2\end{array}$} \\
\hline Age (yrs) & $15-30 n=33$ & & & & \\
\hline & $31-57 n=5$ & $321.99 \pm 30.26$ & $333.6 \pm 27.92$ & $0.012 *$ & $(-) 19.1-(-) 4.1$ \\
\hline \multirow[t]{2}{*}{ Gender } & Male $n=20$ & $314.16 \pm 31.61$ & $351.52 \pm 49.46$ & $0.001^{*}$ & $(-) 58.7-(-) 15.9$ \\
\hline & Female $\mathrm{n}=18$ & $313.48 \pm 25.9$ & $326.35 \pm 36.75$ & $0.04 *$ & $(-) 25.3-(-) 0.4$ \\
\hline \multicolumn{6}{|c|}{ AED } \\
\hline $\mathrm{CBZ}$ & $\mathrm{n}=18$ & $316.18 \pm 31.8$ & $343.43 \pm 52.57$ & $0.02 *$ & $(-)$ 50.8-(-)3.6 \\
\hline PHT & $\mathrm{n}=7$ & $311.81 \pm 26.77$ & $343.5 \pm 23.01$ & $0.06^{\mathrm{ns}}$ & $(-) 66.17-2.79$ \\
\hline VPA & $\mathrm{n}=13$ & $311.68 \pm 26.94$ & $332.19 \pm 44.91$ & $0.01 *$ & $(-) 36.8-(-) 4.1$ \\
\hline \multicolumn{6}{|c|}{ Type of epilepsy } \\
\hline GTCS & $\mathrm{n}=22$ & $311.11 \pm 26.37$ & $333.12 \pm 36.70$ & $0.001^{*}$ & $(-) 34.11-9.9$ \\
\hline Localization & $\mathrm{n}=16$ & $317.59 \pm 32.07$ & $348.51 \pm 54.75$ & $0.02 *$ & $(-) 58.25-(-) 3.58$ \\
\hline \multicolumn{6}{|c|}{ Education status } \\
\hline$<12^{\text {th }}$ std & $\mathrm{n}=23$ & $314.05 \pm 34.08$ & $341.66 \pm 43.73$ & $0.0003^{*}$ & $(-) 40.9-(-) 14.29$ \\
\hline$>12^{\text {th }}$ std & $\mathrm{n}=15$ & $313.50 \pm 18.57$ & $336.43 \pm 48.63$ & $0.09^{\text {ns }}$ & $(-) 50.5-4.69$ \\
\hline \multicolumn{6}{|c|}{ Duration of disease } \\
\hline$\leq 6$ months & $\mathrm{n}=17$ & $308.20 \pm 21.82$ & $341.53 \pm 43.79$ & $0.01 *$ & $(-) 57.6-(-) 9.04$ \\
\hline$>6$ months & $\mathrm{n}=21$ & $318.40 \pm 33.00$ & $338.03 \pm 47.24$ & $0.007^{*}$ & $(-) 33.4-(-)-5.82$ \\
\hline
\end{tabular}

$n s$ - statistically non-significant; * - statistically significant

TABLE 4. Effect of AED on MoCA vs. patient profile

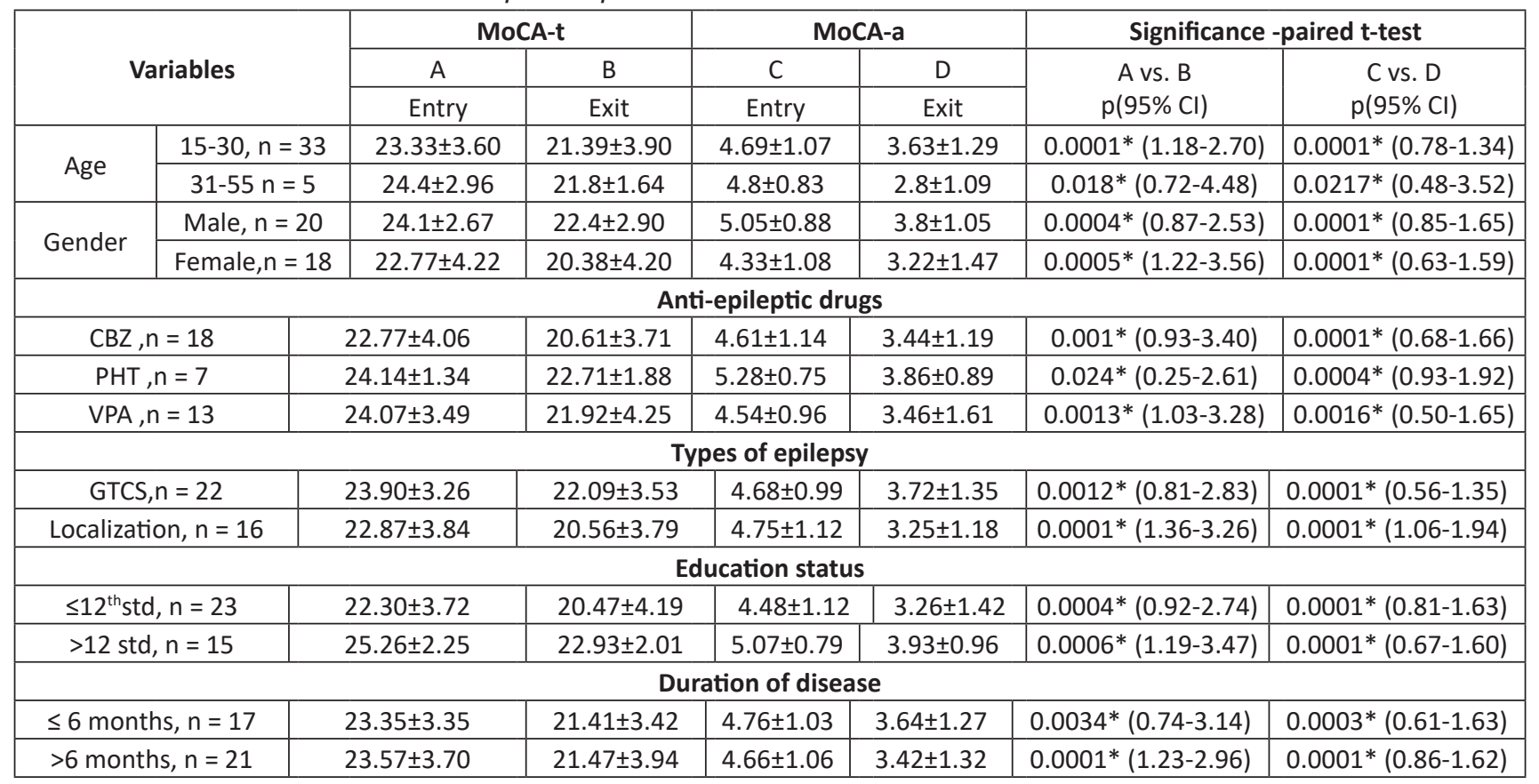


TABLE 5. Effect of AED on TMT and PrM vs. patient profile

\begin{tabular}{|c|c|c|c|c|c|c|c|c|c|c|}
\hline \multicolumn{3}{|l|}{ Variables } & \multicolumn{4}{|c|}{ TMT } & \multicolumn{2}{|c|}{ PrM } & \multicolumn{2}{|l|}{ Significance -paired t-test } \\
\hline & & & \multicolumn{2}{|r|}{$\mathrm{A}$} & \multicolumn{2}{|c|}{$\mathrm{B}$} & C & $\mathrm{D}$ & \multirow{2}{*}{$\begin{array}{l}\text { A vs. B } \\
p(95 \% \mathrm{Cl})\end{array}$} & \multirow{2}{*}{\begin{tabular}{|l} 
Cvs. D \\
p(95\% Cl)
\end{tabular}} \\
\hline & & & \multicolumn{2}{|c|}{ Entry } & \multicolumn{2}{|c|}{ Exit } & Entry & Exit & & \\
\hline \multirow[t]{2}{*}{ Age } & \multicolumn{2}{|c|}{$15-30, n=33$} & \multicolumn{2}{|c|}{$48.11 \pm 37.66$} & \multicolumn{2}{|c|}{$58.29 \pm 42.06$} & $20.48 \pm 6.07$ & $15.03 \pm 6.01$ & $0.036 *(19.66-(-) 0.70)$ & $0.0001 *(3.41-7.50)$ \\
\hline & \multicolumn{2}{|c|}{$31-55 n=5$} & \multicolumn{2}{|c|}{$83.84 \pm 51.86$} & \multicolumn{2}{|c|}{$116.59 \pm 65.0$} & $20.2 \pm 10.08$ & $11.2 \pm 4.96$ & $0.021 *(-57.59-(-) 7.90)$ & $0.030 *(1.35-16.65)$ \\
\hline \multirow[t]{2}{*}{ Gender } & \multicolumn{2}{|c|}{ Male, $n=20$} & \multicolumn{2}{|c|}{$52.14 \pm 38.55$} & \multicolumn{2}{|c|}{$69.88 \pm 48.29$} & $20.5 \pm 7.28$ & $14.3 \pm 5.61$ & $0.002 *(-28.08-(-) 7.39)$ & $0.0003 *(3.25-9.15)$ \\
\hline & \multicolumn{2}{|c|}{ Female, $\mathrm{n}=18$} & \multicolumn{2}{|c|}{$53.55 \pm 44.34$} & \multicolumn{2}{|c|}{$61.60 \pm 50.47$} & $20.38 \pm 5.85$ & $14.77 \pm 6.50$ & $0.288^{\mathrm{ns}}(-23.55-7.44)$ & $0.0005^{*}(2.87-8.35)$ \\
\hline \multicolumn{11}{|c|}{ Anti-epileptic drugs } \\
\hline \multicolumn{2}{|c|}{$\mathrm{CBZ}, \mathrm{n}=18$} & \multicolumn{2}{|c|}{$52.55 \pm 40.73$} & \multicolumn{2}{|c|}{$62.44 \pm 48.33$} & \multicolumn{2}{|c|}{$20.61 \pm 6.09$} & $15.27 \pm 6.75$ & $0.23^{\text {ns }}(-26.95-7.17)$ & $0.0024 *(2.17-8.50)$ \\
\hline \multicolumn{2}{|c|}{$\mathrm{PHT}, \mathrm{n}=7$} & \multicolumn{2}{|c|}{$70.34 \pm 51.77$} & \multicolumn{2}{|c|}{$94.29 \pm 68.35$} & \multicolumn{2}{|c|}{$21.85 \pm 4.94$} & $14.14 \pm 5.27$ & $0.017 *(-42.05-(-)$ 5.83) & $0.0097 *(2.66-12.77)$ \\
\hline \multicolumn{2}{|c|}{$\mathrm{VPA}, \mathrm{n}=13$} & 43.72 & & 55.58 & 3.17 & 19.4 & \pm 8.07 & $13.69 \pm 5.45$ & $0.025 *(-21.95-(-) 1.76$ & $0.003 *(2.38-9.16)$ \\
\hline & & & & & & & Types of epi & & & \\
\hline GTCS, $n=$ & & $42.6 \pm$ & & 55.35 & 2.24 & 20.4 & \pm 6.91 & $15.50 \pm 6.30$ & $0.001 *(-20.04-(-) 5.46)$ & $0.0008 *(2.34-7.57)$ \\
\hline Localizat & $n, n=16$ & 66.85 & 9.78 & 80.54 & 3.54 & 20.4 & \pm 6.25 & $13.18 \pm 5.39$ & $0.16^{\mathrm{ns}}(-33.64-6.24)$ & $0.0001 *(4.20-10.30)$ \\
\hline & & & & & & & Education $\mathrm{s}$ & & & \\
\hline$\leq 12^{\text {th }}$ std, & $n=23$ & 68.88 & 5.19 & 84.08 & 4.18 & 19.4 & \pm 6.96 & $14.13 \pm 6.27$ & $0.039 *(-29.61-(-) 0.77)$ & $0.0001 *(3.20-7.49)$ \\
\hline$>12 \mathrm{std}$, & $=15$ & 28.15 & .99 & 38.17 & 8.03 & 21.9 & \pm 5.78 & $15.13 \pm 5.62$ & $0.005 *(-16.60-(-) 3.43)$ & $0.0024 *(2.84-10.76)$ \\
\hline & & & & & & & Duration of $\mathrm{d}$ & ase & & \\
\hline$\leq 6 \mathrm{mont}$ & $\mathrm{ns}, \mathrm{n}=17$ & 49.87 & 9.72 & 67.37 & 1.19 & 20.1 & \pm 6.46 & $15.64 \pm 6.36$ & $0.0034 *(0.74-3.14)$ & $0.0071 *(1.40-7.55)$ \\
\hline$>6$ mont & $\mathrm{ns}, \mathrm{n}=21$ & 55.18 & & 64.82 & & 20.7 & \pm 6.77 & $13.61 \pm 5.62$ & $0.19^{\text {ns }}(-24.53-5.25)$ & $0.0001 *(4.52-9.67)$ \\
\hline
\end{tabular}

ns - statistically non-significant; ${ }^{*}$ - statistically significant

TABLE 6. Effect of AED on Stroop test vs. patient profile

\begin{tabular}{|c|c|c|c|c|c|c|c|c|}
\hline \multicolumn{3}{|c|}{ Variables } & \multicolumn{2}{|c|}{ Stroop 1} & \multicolumn{2}{|c|}{ Stroop 2} & \multicolumn{2}{|c|}{ Significance -paired t-test } \\
\hline & & & A & \multirow[b]{2}{*}{ Exit } & $\mathrm{C}$ & \multirow[t]{2}{*}{$\mathrm{D}$} & \multirow{2}{*}{$\begin{array}{l}\text { A vs. B } \\
\text { p }(95 \% \mathrm{Cl})\end{array}$} & \multirow{2}{*}{$\begin{array}{l}\text { C vs. D } \\
\text { p }(95 \% \mathrm{Cl})\end{array}$} \\
\hline & & & Entry & & Entry & & & \\
\hline \multirow[t]{2}{*}{ Age } & \multicolumn{2}{|c|}{$15-30, n=33$} & $14.36 \pm 1.72$ & $13.24 \pm 2.20$ & $22.82 \pm 2.01$ & $21.21 \pm 2.92$ & $0.0005 *(0.53-1.71)$ & $0.0001 *(1.01-2.20)$ \\
\hline & \multicolumn{2}{|c|}{$31-55 n=5$} & $14.4 \pm 1.14$ & $12.2 \pm 1.64$ & $22.40 \pm 1.52$ & $20.60 \pm 0.89$ & $0.062^{\text {ns }}(-0.19-4.59)$ & $0.12^{\text {ns }}(-0.74-4.34)$ \\
\hline \multirow[t]{2}{*}{ Gender } & \multicolumn{2}{|c|}{ Male, $\mathrm{n}=20$} & $14.5 \pm 1.39$ & $13.05 \pm 1.57$ & $22.75 \pm 1.62$ & $22.10 \pm 1.62$ & $0.0005 *(0.73-2.17)$ & $0.0001 *(0.98-2.32)$ \\
\hline & \multicolumn{2}{|c|}{ Female, $\mathrm{n}=18$} & $14.22 \pm 1.92$ & $13.16 \pm 2.70$ & $22.78 \pm 2.29$ & $21.17 \pm 3.67$ & $0.0326 *(0.10-2.01)$ & $0.0033 *(0.61-2.61)$ \\
\hline \multicolumn{9}{|c|}{ Anti-epileptic drugs } \\
\hline \multicolumn{2}{|c|}{$\mathrm{CBZ}, \mathrm{n}=18$} & \multicolumn{2}{|c|}{$14.33 \pm 1.53$} & $13.11 \pm 2.34$ & $22.78 \pm 1.83$ & $21.06 \pm 3.10$ & $0.0007 *(0.78-2.34)$ & $0.0009 *(0.82-2.62)$ \\
\hline \multicolumn{2}{|c|}{ PHT,$n=7$} & \multicolumn{2}{|c|}{$14.71 \pm 1.79$} & $13.28 \pm 1.11$ & $23.43 \pm 1.27$ & $21.43 \pm 1.81$ & $0.0161 *(0.49-2.71)$ & $0.038 *(0.15-3.85)$ \\
\hline \multicolumn{2}{|c|}{ VPA,$n=13$} & 14. & $23 \pm 1.83$ & $13.0 \pm 1.83$ & $.54 \pm 0.96$ & $3.46 \pm 1.61$ & $0.0189 *(0.24-2.12)$ & $0.0066 *(0.44-2.18)$ \\
\hline \multicolumn{9}{|c|}{ Types of epilepsy } \\
\hline \multicolumn{2}{|c|}{ GTCS, $n=22$} & \multicolumn{2}{|c|}{$14.18 \pm 1.70$} & $13.5 \pm 2.06$ & $22.68 \pm 2.03$ & $21.55 \pm 2.74$ & $0.060^{\text {ns }}(-0.03-1.41)$ & $0.0025 *(0.45-1.82)$ \\
\hline \multicolumn{2}{|c|}{ Localization, $n=16$} & 14 & $.62 \pm 1.58$ & $15.56 \pm 2.22$ & $22.88 \pm 1.86$ & $20.56 \pm 2.73$ & $0.0001 *(1.23-2.90)$ & $0.0001 *(1.41-3.22)$ \\
\hline \multicolumn{9}{|c|}{ Education status } \\
\hline \multicolumn{2}{|c|}{$\leq 12^{\text {th }}$ std, $n=23$} & \multicolumn{2}{|c|}{$13.86 \pm 1.79$} & $12.47 \pm 2.35$ & $22.48 \pm 2.11$ & $20.70 \pm 3.07$ & $0.0044 *(0.48-2.30)$ & $0.0002 *(0.94-2.63)$ \\
\hline \multicolumn{2}{|c|}{$>12 \mathrm{std}, \mathrm{n}=15$} & 15. & $13 \pm 1.06$ & $14.06 \pm 1.38$ & $23.20 \pm 1.61$ & $21.80 \pm 2.08$ & $0.0004 *(0.58-1.56)$ & $0.0006 *(0.71-2.09)$ \\
\hline \multicolumn{9}{|c|}{ Duration of disease } \\
\hline \multicolumn{2}{|c|}{$\leq 6$ months, $\mathrm{n}=17$} & \multicolumn{2}{|c|}{$14.17 \pm 1.74$} & $13.52 \pm 2.09$ & $22.71 \pm 2.02$ & $21.59 \pm 3.39$ & $0.142^{\text {ns }}(-0.24-1.54)$ & $0.018 *(0.21-2.02)$ \\
\hline \multicolumn{2}{|c|}{$>6$ months, $\mathrm{n}=21$} & \multicolumn{2}{|c|}{$14.52 \pm 1.60$} & $12.76 \pm 2.18$ & $21.81 \pm 1.91$ & $20.76 \pm 2.10$ & $0.0001 *(1.04-2.48)$ & $0.0001 *(1.34-2.76)$ \\
\hline
\end{tabular}

ns - statistically non-significant; * - statistically significant

tion (true positives), in 6 the latency did not prolong (false negative). Out of the 7 patients, who did not show deterioration in MoCA-t scores, 5 had prolonged latency of P300 (false positive), remaining 2 had no prolongation (true negative). Taking this into consideration the sensitivity of P300 for picking up cognitive dysfunction was $80.64 \%$, specificity being $28.57 \%$.

Similarly the sensitivity and specificity of other test was also calculated for identifying cognitive deterioration. PrM and MoCA-a had a sensitivity of around $87 \%$ with specificity of 28.5 and $25 \%$ respectively. Sensitivity of TMT was $90.3 \%$ (specificity $28.5 \%$ ), Stroop-1 80.6\% (specificity $42.7 \%$ ) and Stroop-2 $74.2 \%$ (specificity 57\%).

\section{DISCUSSION}

The attention is an important cognitive domain quintessential for smooth execution of certain 
skilled activities like driving and learning [28]. The cognitive dysfunction are known to be present in PWE and might be the cause of the learning disability seen in PWE [1]. The dysfunction is often attributed to either the epileptic processes, seizure frequency and/or polypharmacy $[3,13,29,30]$. Accordingly, regular monitoring of the cognitive functions has been recently advocated in PWE on AED [31]. Although the adverse effects of AED on cognition has been investigated previously, but not prospectively $[13,14]$. In most of the previous research the duration of the pharmacotherapy prior to cognitive evaluation was not uniform and the severity of epilepsy was also varying.

We present the first prospective study, to best of our knowledge, exploring the effects of AEDs on cognition and attention. Average duration of exposure to AED in our study population was $107.8 \pm$ 19.2 days. Further the subjects were either drug naïve or were not exposed to AED within six months prior to their inclusion and the duration of disease was mostly less than 12 months.

Our results suggest that AED have a profound adverse effect on over all cognition (tested by MoCA-t scores). The working memory and attention in our patients, tested by PrM and TMT, was significantly affected post pharmacotherapy. This was further confirmed by deteriorating performance on Stroop test and MoCA-a, both of them specifically evaluate the attention domain of cognition [32]. P300 latency is an accepted marker of attention which remains temporally stable and unaffected over the course of time in a healthy individual [33]. Following exposure to AED we found P300 latency prolongation in $78.94 \%$ subjects.

In contrast to previous work our results suggest that pharmacotherapy with a single AED affects cognition adversely [15]. Park et al. in a review could not prove the cognitive effects of AED when given for a short period of up to a year [30]. We found that cognitive functions deteriorate even with an exposure to AED for a short duration of $107.8 \pm 19.2$ days. Further, it seems that this detrimental effect is independent of the duration of disease and education status.

Further, our results show that neither the seizure type nor the type of AEDs prescribed is immune to cognitive adverse effects. Our results are in agreement with Kubota et al., who did not find significant correlation between seizure type and adverse cognitive effects of AED [13].

In addition our results suggest that different variables produce different results on various cognitive tests deployed by us. For example on MoCA-t, our reference tool, exposure to CBZ, PHT or VPA showed significant cognitive impairment. While applying TMT and P300 tests CBZ and PHT, respectively, did not show significant abnormality at exit point. It is noteworthy the cognitive deterioration was mostly subclinical. In our study population ( $\mathrm{n}=38)$ only $13.15 \%(\mathrm{n}=5)$ report deteriorating cognitive symptoms. None of these 5 persons showed cognitive deterioration in all the evaluation tools used by us. Therefore, it seems that no single battery can give a holistic view of cognition affection by AEDs.

Compared to our reference test (MoCA-t) the sensitivity and specificity of P300 ERP, for diagnosing cognitive decline due to AED, was $80.64 \%$ and $28.5 \%$ respectively. This finding is in agreement with previous research which found the P300 to be $80 \%$ sensitive in identifying minimal cognitive decline [9].

Given the differential ability of different tools in identifying subclinical cognitive deterioration combined use of various tests has been suggested previously [9]. Considering ease of administration, its non sensitivity to trans-cultural and educational status, the P300 ERP could be a reasonable screening test for monitoring the cognitive functions in PWE.

\section{Limitations of our study}

There was no arm with healthy controls and the serum concentration of AEDs was not available for correlation with the cognitive ill effects of the drugs.

\section{CONCLUSIONS}

The overall cognitive functions are adversely affected by epilepsy pharmacotherapy. The ill effects of AED on domain of attention are seen after an average exposure of 15 weeks. Thus a close monitoring of these side effects of AED is needed to enable a timely intervention. P300 ERP, not constrained by trans-cultural and educational differences, can be used as a handy screening tool for monitoring PWE on AED. 


\section{REFERENCES}

1. Beghi $M$, Cornaggia CM, Frigeni $B$, Beghi E. Learning disorders in epilepsy. Epilepsia. 2006;47 Suppl 2:14-8.

2. Wilson SJ, Baxendale $\mathrm{S}$, Barr W, et al. Indications and expectations for neuropsychological assessment in routine epilepsy care: report of the ILAE Neuropsychology Task Force, Diagnostic Methods Commission, 2013-2017. Epilepsia. 2015;56:674-681.

3. Witt JA, Helmstaedter C. Monitoring the cognitive effects of antiepileptic pharmacotherapy - approaching the individual patient. Epilepsy Behav. 2013 Mar;26(3):450-6.

4. Coen RF, Robertson DA, Kenny RA, King-Kallimanis BL. Strengths and Limitations of the MoCA for Assessing Cognitive Functioning: Findings From a Large Representative Sample of Irish Older Adults. J Geriatr Psychiatry Neurol. 2016 Jan;29(1):18-24.

5. Nasreddine ZS, Phillips NA, Bédirian V, Charbonneau S, Whitehead V, Collin I, Cummings JL, Chertkow H. The Montreal Cognitive Assessment, MoCA: a brief screening tool for mild cognitive impairment. J Am Geriatr Soc. 2005 Apr;53(4):695-9.

6. Gómez F, Zunzunegui M, Lord C, Alvarado B, García A. Applicability of the MoCA-S test in populations with little education in Colombia. Int J Geriatr Psychiatry. 2013 Aug;28(8):813-20.

7. Sutton S, Braren M, Zubin J, John ER. Evoked-potential correlates of stimulus uncertainty. Science. 1965 Nov 26;150(3700):1187-8.

8. Howe AS, Bani-Fatemi A, De Luca V. The clinical utility of the auditory P300 latency subcomponent event-related potential in preclinical diagnosis of patients with mild cognitive impairment and Alzheimer's disease. Brain Cogn. 2014 Apr;86:64-74.

9. Parra MA, Ascencio LL, Urquina HF, Manes F, Ibáñez AM. P300 and neuropsychological assessment in mild cognitive impairment and Alzheimer dementia. Front Neurol. 2012 Dec 5;3:172.

10. Kaga $Y$, Kanemura H, Ishii S, Kaga S, Aihara M. Event-related potentials for cognitive assessment of patients with epilepsy. Pediat Therapeut. 2013;3(3):161.

11. KuJan-Mar N, Gupta M, Sahay M, Motiani R, Hussain S. P300 as a marker of cognitive dysfunction in chronic epileptics. Neurol India. 1996 Apr-Jun;44(2):63-66.

12. Triantafyllou $\mathrm{NI}$, Zalonis I, Kokotis $\mathrm{P}$, Anthracopoulos M, et al. Cognition in epilepsy: A multichannel event-related potential (P300) study. Acta Neurol Scand. 1992;86:462-465.

13. Kubota F, Kifune A, Shibata N, Akata T, Takeuchi K, Takahashi S. Study on the P300 of Adult Epileptic Patients (Unmedicated and Medicated Patients). J Epilepsy. 1998;11:325-331.

14. Tumay Y, Altun Y, Ekmekci K, Ozkul Y. The effects of levetiracetam, carbamazepine, and sodium valproate on P100 and P300 in epileptic patients. Clin Neuropharmacol. 2013;36:55-58.

15. Craig I, Tallis R. Impact of valproate and phenytoin on cognitive function in elderly patients: results of a single-blind randomized comparative study. Epilepsia. 1994;35:381-90.

16. Vining EPG, Mellits ED, Dorsen MM, et al. Psychologic and behavioral effects of antiepileptic drugs in children: a double blind comparison between phenobarbital and valproic acid. Pediatrics. 1987;80:165-74.

17. Meador KJ, Loring DW. Cognitive effects of antiepileptic drugs. In: Devinsky 0 , Theodore W, eds. Epilepsy and behavior. New York: Wiley-Liss, 1991:151-170.

18. Meador KJ, Loring DW, Moore EE, et al. Comparative cognitive effects of phenobarbital, phenytoin, and valproate in healthy adults. Neurology. 1995;45:1494-9.

19. https://www.mocatest.org/contact.

20. Gupta M, Gupta V, Nagar Buckshee R, Sharma V. Validity and reliability of hindi translated version of Montreal cognitive assessment in older adults. Asian J Psychiatr. 2019 Oct;45:125-128.

21. Golden CJ. Stroop color and word test. A manual for clinical and experimental uses. Chicago: Stoelting, 1978.

22. Parkington JE, Leiter RG. Partington's Pathway Test. The Psychological Service Center Bulletin. 1949;1:9-20.

23. Meador KJ, Loring DW, Allen ME, Moore EE, Zamrini EY, King DW. Effects of carbamazepine and phenytoin on EEG and memory in healthy adults. Epilepsia. 1993;34:153-157.

24. Duncan CC, Barry RJ, Connolly JF, Fischer C, et al. Event-related potentials in clinical research: Guidelines for eliciting, recording, and quantifying mismatchnegativity, P300, and N400. Clin Neurophysiol. 2009;120:1883-1908.

25. Pirozzo S, Papinczak T, Glasziou P. Whispered voice test for screening for hearing impairment in adults and children: systematic review. BMJ. 2003 Oct 25;327(7421):967.

26. Russotto DT, Landau WM, Harding GW, Bohne B A et al. Calibrated finger rub auditory screening test (CALFRAST). Neurology. 2009;72(18):1595-1600.

27. Fabiani M, Gratton G, Karis D, Donchin E. Definition, identification, and reliability of measurement of the P300 component of the event-related brain potential. Adv Psychophysiol. 1987;2:1-78.

28. Lundqvist $A$. Cognitive functions in drivers with brain injury. Anticipation and adaptation. Doctoral Dissertation. Linkoping, Sweden; 2001.

29. Sowndhararajan K, Kim M, Deepa P, Park SJ, Kim S. Application of the P300 Event-Related Potential in the Diagnosis of Epilepsy Disorder: A Review. Sci Pharm. 2018 Mar 26;86(2):10.

30. Park SP, Kwon SH. Cognitive effects of antiepileptic drugs. Journal of Clinical Neurology (Seoul, Korea). 2008;4(3):99-106.

31. Wilson SJ, Baxendale S, Barr W, et al. Indications and expectations for neuropsychological assessment in routine epilepsy care: report of the ILAE Neuropsychology Task Force, Diagnostic Methods Commission, 2013-2017. Epilepsia. 2015;56:674-681.

32. MacLeod CM. The Stroop task: the "gold standard" of attentional measures. J Exp Psychol Gen. 1992;121:12-14.

33. Karniski W, Blair RC. Topographical and temporal stability of the P300. Electroencephalogr Clin Neurophysiol. 1989 May; 72(5):373-83. 